\title{
CRYOGENIC HEAT TREATMENT - A REVIEW OF THE CURRENT STATE
}

\author{
Kamran Amini $^{1 *}$, Amin Akhbarizadeh ${ }^{1}$ \\ ${ }^{1}$ Department of Mechanical Engineering, Tiran Branch, Islamic Azad \\ University, Isfahan, Iran
}

Received 21.10.2016

Accepted 08.03.2017

\begin{abstract}
The deep cryogenic heat treatment is an old and effective heat treatment, performed on steels and cast irons to improve the wear resistance and hardness. This process includes cooling down to the liquid nitrogen temperature, holding the samples at that temperature and heating at the room temperature. The benefits of this process are significant on the ferrous materials, but recently some studies focused on other nonferrous materials. This study attempts to clarify the different behavior of some materials subjected to the deep cryogenic heat treatment, as well as explaining the common theories about the effect of the cryogenic heat treatment on these materials. Results showed that polymers exhibit different behavior regarding to their crystallinity, however the magnesium alloys, titanium alloys and tungsten carbide show a noticeable improvement after the deep cryogenic heat treatment due to their crystal structure.
\end{abstract}

Keywords: Deep Cryogenic Treatment; Tungsten carbide; Magnesium and Titanium alloys; Polymers; Composites.

\section{Introduction}

Cryogenic heat treatment was introduced to the industries in the 1920s. This special kind of supplementary heat treatment plays an important role in selecting the finishing production procedure of parts with the lowest wear rate, the lowest austenite percentage and the lowest economic cost. This specific heat treatment is classified into two different groups: (i) the shallow cryogenic heat treatment performed at temperatures higher than $125 \mathrm{~K}$, and (ii) the deep cryogenic heat treatment attributed to the treatments in which samples are cooled down to lower temperatures (125-77 K)[1-3].

The main effect of the cryogenic heat treatment of steels is the elimination of the retained austenite. Another effect that is observed only in the deep cryogenic treatment is the reduction of the carbides size, increasing its percentage and making a more

\footnotetext{
*Corresponding author: Kamran Amini, K_amini@iautiran.ac.ir
} 
homogenized carbide distribution [4-8]. These microstructural changes occur as a consequence of the carbon atoms jumping at lower temperature due to the high degree of the contraction in the steel structure. These wandering carbon atoms jump to the neighboring sites and act as appropriate places for the eta chromium carbide nucleation in the prior tempering. These new carbides increase the carbides percentage and make a more homogenous carbide distribution in the steel and cast iron materials after the deep cryogenic treatment $[4,6,9-16]$.

This improvement is considerably important in the tools, such as gears, brakes, rotors, bearings, pinion shafts, crown wheels and dies [17], whose wear resistance is the most essential factor in the tool life.

The deep cryogenic heat treatment is applied on a wide range of ferrous materials including carburized steels [11, 18-20], high speed steels [21-23] and tool steels [10, 22, 24-32]. Recent studies has been focused on the deep cryogenic heat treatment effect on the tungsten carbide [27, 30-33], magnesium alloys [34, 35] and composites and polymers [36, 37].

In this study the deep cryogenic heat treatment of different materials including tungsten carbide, polymers and their composites, magnesium and titanium alloys, were reviewed to study the effect of this treatment and the theories about this phenomenon on these materials.

\section{Deep cryogenic heat treatment}

\section{Tungsten carbide}

Tungsten carbide is one of the most useful materials for cutting tools. Tungsten carbide is a ceramic compound regularly used with cobalt as the binder to create cutting tool bits. Cobalt fulfills the space between the tungsten carbide powders and during the sintering a homogenous tool is produced (Fig. 1) [30-33, 38]. The tools produced by tungsten carbide show 10 times longer working life as compared with the HSS tools [39]. A WC-Co tool consists of four phases:

1- Alpha ( $\alpha$-phase) which is formed from tungsten carbide (WC) and has a hexagonal structure with central carbon atoms (Fig. 2).

2 - Beta ( $\beta$ - phase) which is the cobalt phase and has a hexagonal structure at room and the FCC structure at the temperature above $416{ }^{\circ} \mathrm{C}$. It is worth mentioning that cobalt occupies the next site in the Periodic table after iron and has similar structure and valence band and shows behaviors similar to iron.

3- Gamma ( $\gamma$-phase) that consists of the cubic lattice carbides like $\mathrm{TaC}$, TiC, etc.

4- Eta ( $\eta$-phase) consists of multiple carbides including tungsten and at least one metal binder. These carbides are generally cobalt bonded carbides like $\left(\left(\mathrm{CoW}_{3}\right) \mathrm{C}\right.$ and $\left(\left(\mathrm{Co}_{6} W_{3}\right) C\right)$ (Fig. 3) [33, 40, 41].

Most of the studies show that cryogenic heat treatment improves the wear behavior of the WC-Co tools specifically at low temperatures and not long working cycles [30-33, 38-41]. In other words, at high temperatures, the cryogenic heat treatment loses its ability in improving the wear resistance [32, 33].

This improvement is explained via formation of the new $\eta$ carbides during the cryogenic treatment. These newly formed carbides show a more uniform distribution with higher percentage and considerably improve the wear behavior. This phase fulfills the empty spaces between the structure and hence creates a more coherent structure with 
a more dense particle distribution [30, 31, 33, 41]. Moreover, a dense structure leads to a more thermal coefficient that increases the tool life due to the higher thermal resistance [41]. Some studies also show that increasing the $\eta$ phase leads to a decrease in the $\beta$ phase, which intensifies the wear resistance improvement $[30,40]$.

Beyond the $\eta$ phase precipitation, $\beta$ phase reduction and formation of a denser structure with a higher thermal conductivity, a stress relaxation is also observed in the cryogenically treated tungsten carbide tools. This stress relaxation improves the tool life because of lowering the risk of the stress-induced fractures. This stress is produced during the sintering due to a difference in thermal expansion coefficient between the WC powder and the cobalt binder [27, 33, 40]. Beyond this, it was also revealed that the tungsten solubility in the Co phase decreases as the consequence of the Co phase transformation during the deep cryogenic heat treatment and hence the tungsten precipitates increase (Fig. 4) [42, 43].

It was also shown that the deep cryogenic heat treatment improves the wear resistance vividly in $\mathrm{WC}-\mathrm{Fe}-\mathrm{Ni}$ cemented carbides due to the martensitic transformation in the binder phase as well as increasing the content of the $\alpha-(\mathrm{Fe}, \mathrm{Ni})$
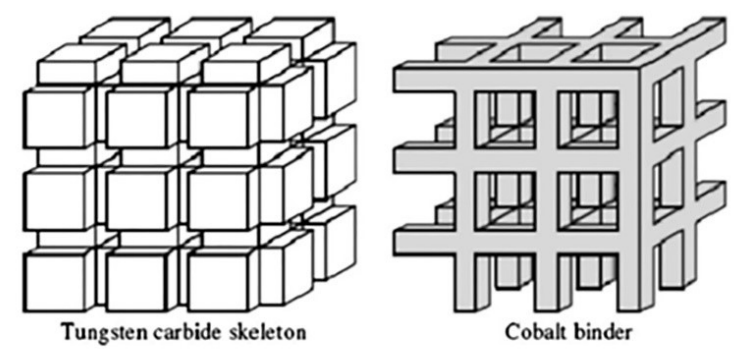

Fig. 1. Schematic representation of a WC-Co composite tool [33].

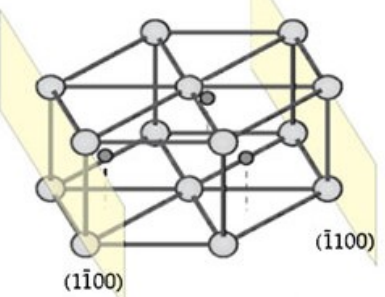

$\bigcirc \mathrm{W}$

$\circ \mathrm{C}$

Fig. 2. Schematic representation of WC hexagonal structure [33]. 


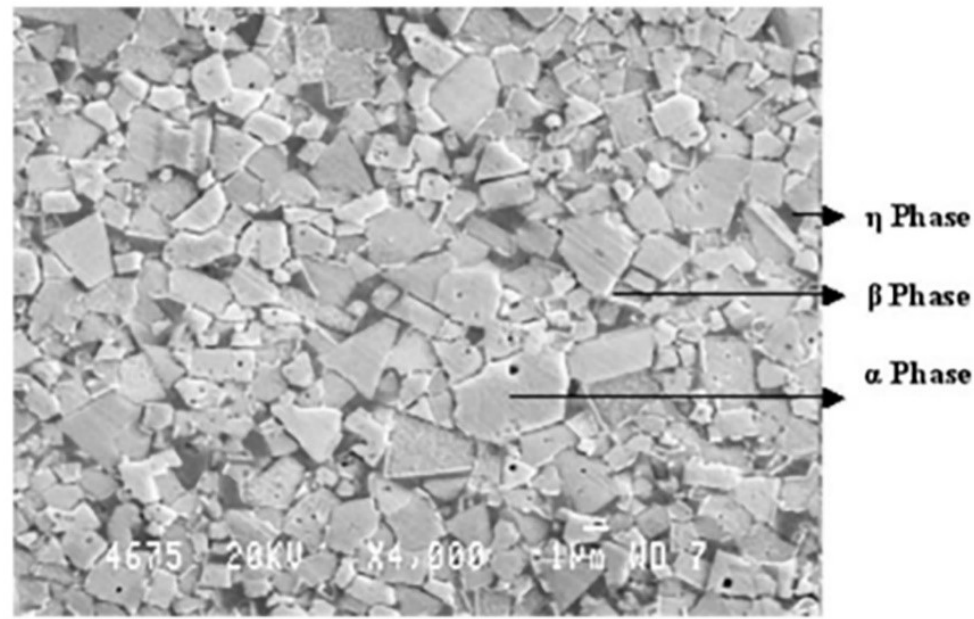

Fig. 3. Surface microstructure of WC-Co cutting tool after etching according to ASTM B390 [30].

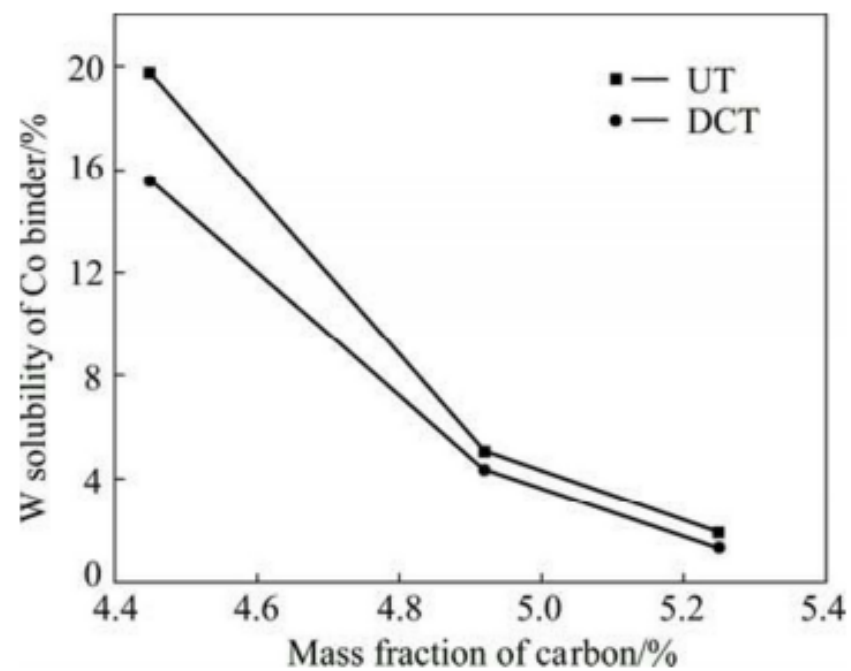

Fig. 4. The effect of the deep cryogenic heat treatment on the tungsten solubility in the Co phase[42].

Polymers and their composites

Wear behavior of polymers is important in many applications. Polymers demonstrate different behaviors after the cryogenic heat treatment [17, 36, 37]. Polytetrafluoroethylene (PTFE) shows $\sim 60 \%$ and polyetherimide (PEI) shows $\sim 30 \%$ wear improvement after the deep cryogenic heat treatment. In spite of this improvement, polyimide (PI) and copolymer PEI do not show considerable changes (Fig. 5) [36]. 
The DSC and XRD analyses of the amorphous or semi-amorphous polymers (PEI and PI) show a noticeable increase in the crystallinity due to the deep cryogenic heat treatment. It is also observed that deep cryogenic heat treatment increases the residual stress that enhances the wear resistance of PEI. In the completely crystalline polymers, the glass transition temperature $\left(\mathrm{T}_{\mathrm{g}}\right)$ does not change, but the wear resistance will be improved. This can be the consequence of agglomeration and fibrillation phenomena produced in the PTFE structure during the deep cryogenic treatment (Fig. 6) [36]. It is also clarified that deep cryogenic heat treatment transfers the molecules to the new situation to occupy less space and decreases the random orientation. This phenomenon produces a denser polymer with improved bonding strength which leads to a better wear behavior as compared with the un-treated polymers [37].

It is also revealed that cryogenic treatment of the composites with short glass fibers is not beneficial due to the disbonding occurred in the contact surface of the resin and fibers. In spite of these results, the cryogenic treatment of the PTFE fiber epoxies is beneficial for wear improvement due to its effect in the PTFE structure [36].

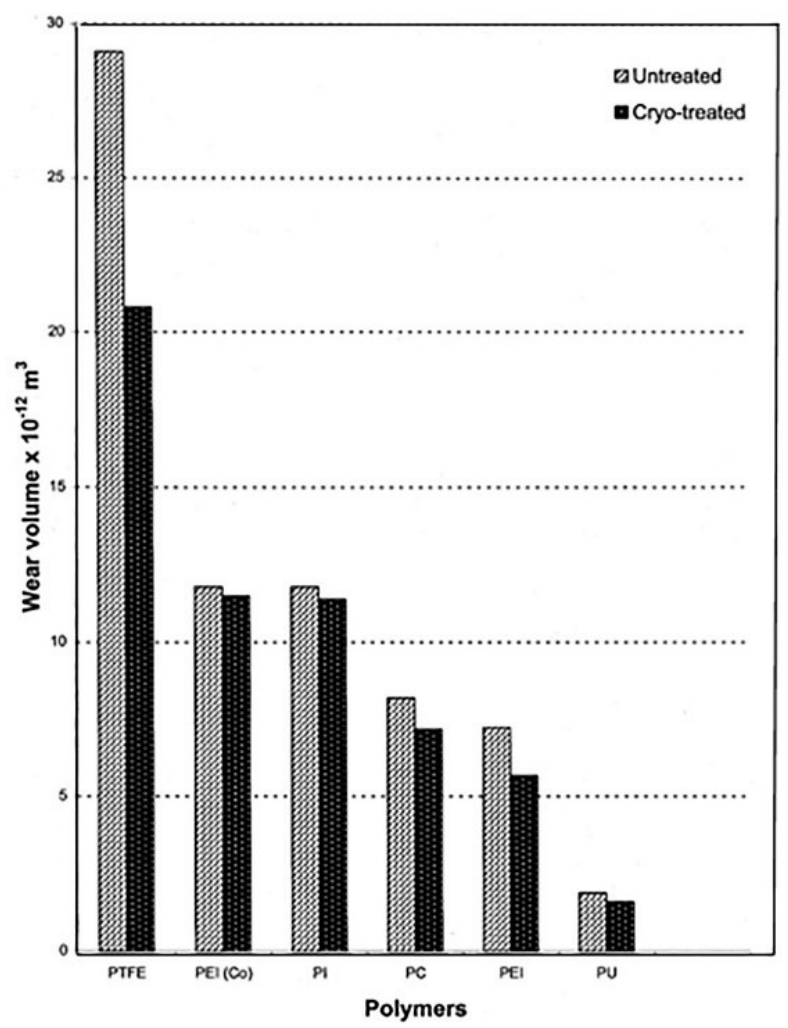

Fig.5. Wear behavior of different cryogenically treated and not-treated polymers [36]. 

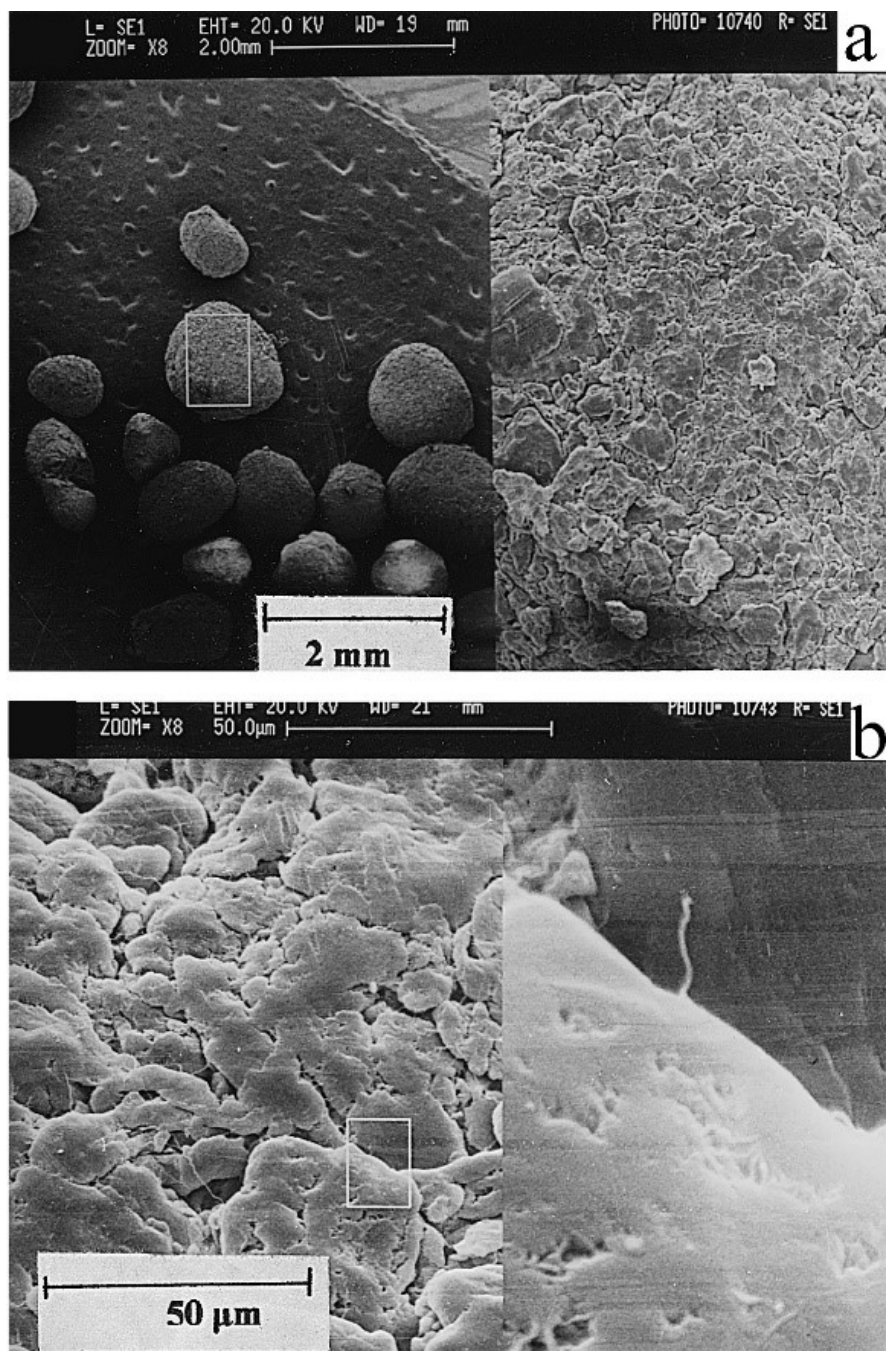

Fig. 6. SEM micrograph of PTFE polymer, (a) un-treated and (b) cryotreated [36].

\section{Metallic materials}

Magnesium alloys

Magnesium alloys are used because to their lower weight (as compared with steel and aluminum), significant strength to weight ratio [44], as well as good machinability, substantial damping capacity and electromagnetic shielding characteristics [44, 45]. AZ91 is one of the most popular alloys of magnesium due to its easy casting, significant ductility and noticeable machinability. The microstructure of AZ91 contains the HCP magnesium phase ( $\alpha$ phase) and $\mathrm{BCC}$ intermetallic compound of $\mathrm{Mg}_{17} \mathrm{Al}_{12}$ ( $\beta$ phase) $[46,47]$.

It was shown that cryogenic treatment of AZ91 after casting improves the mechanical properties and corrosion resistance of AZ91 due to changing the $\beta$ phase 
distribution after the cryogenic treatment $[35,48]$. It was also revealed that deep cryogenic heat treatment of the AZ91 slightly improved the hardness and wear behavior of the alloy due to its effect on the alloy microstructure [34]. This improvement is a consequence of structure contraction, which takes place at low temperatures. Aluminum atoms in the $\beta$ phase were forced to jump to the nearby defects due to structure contraction. These atoms would be precipitated as the new $\mathrm{Mg}_{17} \mathrm{Al}_{12}$ precipitates during aging (Fig. 7). Moreover, the expansion coefficients of the $\alpha$ and $\beta$ phases are different. At low temperatures, this difference leads to different shrinkage values, and subsequently some dislocations and micro voids would be produced in the boundaries of the phases. These newly formed defects are appropriate places for aluminum atoms jumping during the deep cryogenic heat treatment. These atoms would act as preferential sites for precipitates to be nucleated during aging [34].

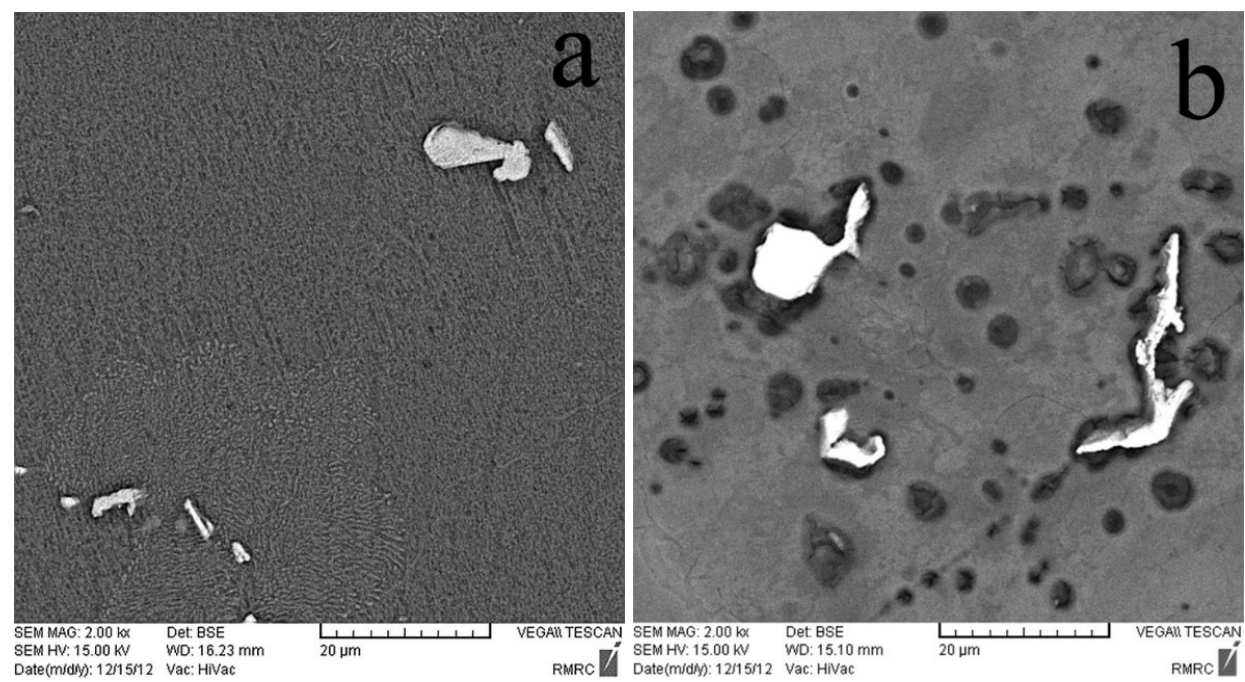

Fig. 7.SEM micrographs of (a) water cooled and (b) water cooled and deep cryogenically treated, AZ91 samples after etching in picral etchant at the magnification of $2.00 \mathrm{KX}$ [34].

Titanium alloys

Titanium is vastly uses due to its resistance to corrosive environments as well as acceptable mechanical properties and lower weight to strength as compared with the steels [49]. Different studies were carried out to investigate the effect of the deep cryogenic heat treatment on different alloys of the titanium including, nickel-titanium endodontic [50], Ti-6246 titanium alloy [51] and $\mathrm{Ti}-6 \mathrm{Al}-4 \mathrm{~V}$ alloy [49, 52]. These studies showed that the deep cryogenic heat treatment increases the hardness and decreases the wear rate of the titanium alloys. It was also revealed that the deep cryogenic heat treatment reduced the friction coefficient of the Ti-6Al-4V alloys. These changes are intensified in longer holding durations at the deep cryogenic temperatures. These phenomena can be related to the reduction of the grain size and the $\beta$ phase. Moreover, it was clarified that a high number of dislocations and twins are produced during the deep cryogenic heat treatment are responsible for the wear resistance and hardness improvement [49]. During the deep cryogenic heat treatment, titanium 
structure endures a high degree of contraction. The high degree of contraction as well as different thermal expansion coefficient of the $\alpha$ and $\beta$ phase, produces a high degree of newly formed dislocations and twins. In longer holding durations, the content of these defects increases due to a higher degree of contraction and hence longer holding durations, increase the improvement of the wear resistance and hardness of the deep cryogenically treated samples (Fig. 8) [49, 52].

a

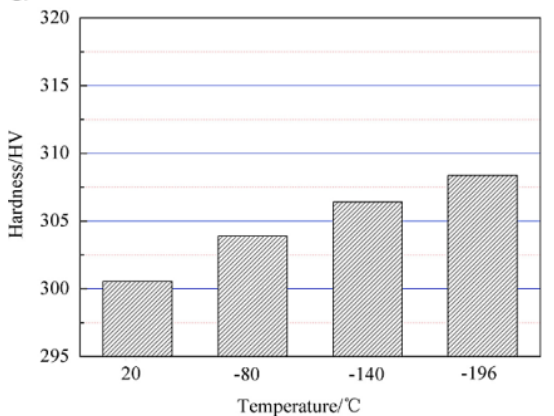

b

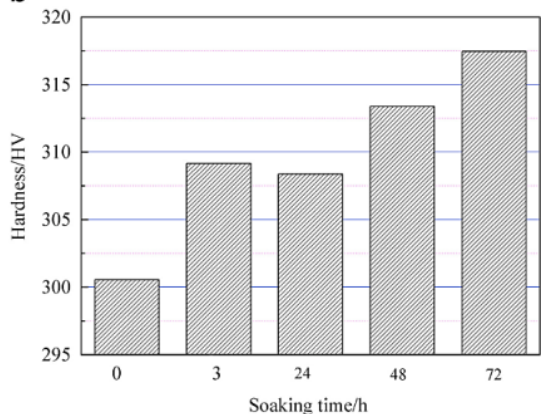

Fig. 8. Hardness of Ti-6Al-4V titanium alloy at different temperatures (a) and during different holding durations (b) at liquid nitrogen temperature [49].

\section{Conclusion}

This study represents a literature review of different materials including tungsten carbide, polymers and their composites, magnesium and titanium alloys.

It was documented that different polymers show different behaviors, ranging from vivid improvement to vivid reduction in hardness and wear resistance, after the deep cryogenic treatment as a consequence of their crystal structure. It was also showed that the hardness and wear resistance are improved in tungsten carbide, titanium and magnesium alloys after the deep cryogenic heat treatment. These behaviors of tungsten carbide are consequence of the $\eta$ carbides formation, $\beta$ phase reduction, formation of a denser structure with a higher thermal conductivity and a stress relaxation in the structure. In the magnesium alloys this behavior is related to the precipitation of the $\mathrm{Mg}_{17} \mathrm{Al}_{12}$ during the aging treatment. The hardness and wear resistance improvement of the titanium alloys is assumed to be a consequence of the grain size and the $\beta$ phase reduction as well as increasing the number of dislocations and twins due to the deep cryogenic heat treatment.

\section{References}

[1] A. Akhbarizadeh, K. Amini, S. Javadpour: Materials \& Design, 35 (2012) 484-490.

[2] N.S. Kalsi, R. Sehgal, V.S. Sharma: Materials and Manufacturing Processes, 25 (2010) 1077-1100.

[3] D.K. Paul Cohen: Cutting Tool Engineering, 50 (1998) 46-50.

[4] V. Bulancea, D. Condurache, D.A. Gheorghiu: Annals of the University of Craiova, Electrical Engineering Series, 32 (2008) 342-345.

[5] K. Amini, S. Nategh, A. Shafiey, M.A.Soltany: To Study the effect of cryogenic heat treatment on hardness and the amount of residual austenite in 1.2304 steel. In: 
Proceedings of the 17Th International Metallurgical and Materials Conference, Czech Republic, 13-15 May 2008, p. 1

[6] K. Amini, S. Nategh, A. Shafyei, A. Rezaeian: International Journal of Minerals, Metallurgy, and Materials, 19 (2012) 30-37.

[7] A. Akhbarizadeh, K. Amini, S. Javadpour: Materials \& Design, 41 (2012) 114-123.

[8] K. Amini, A. Akhbarizadeh, S. Javadpour: Vacuum, 86 (2012) 1534-1540.

[9] A. Akhbarizadeh, S. Javadpour: Materials Letters, 93 (2013) 247-250.

[10] K. Amini, S. Nategh, A. Shafyei: Materials \& Design, 31 (2010) 4666-4675.

[11] A. Bensely, S. Venkatesh, D. Mohan Lal, G. Nagarajan, A. Rajadurai, K. Junik: Materials Science and Engineering: A, 479 (2008) 229-235.

[12] H. Paydar, K. Amini, A. Akhbarizadeh: Kovove Materialy-Metallic Materials, 52 (2014) 163-169.

[13] H.-h. Liu, J. Wang, H.-s. Yang, B.-1. Shen, S.-j. Gao, S.-j. Huang: Journal of Iron and Steel Research, International, 13 (2006) 43-48.

[14] T.K. Meng F, Azuma R, Sohma H: ISIJ International, 34 (1994) 205-210.

[15] K. Amini, MR. Hoda, A. Shafyei: Metal Science and Heat Treatment, 55 (2014) 683.

[16] S. Zhirafar, A. Rezaeian, M. Pugh: Journal of Materials Processing Technology, 186 (2007) 298-303.

[17] C.D. P. Baldissera: The Open Mechanical Engineering Journal, 2 (2008) 1-11.

[18] P. Baldissera, C. Delprete: Materials \& Design, 30 (2009) 1435-1440.

[19] A. Bensely, A. Prabhakaran, D. Mohan Lal, G. Nagarajan: Cryogenics, 45 (2005) 747-754.

[20] A. Bensely, D. Senthilkumar, D. Mohan Lal, G. Nagarajan, A. Rajadurai: Materials Characterization, 58 (2007) 485-491.

[21] F.J. Da Silva, S.D. Franco, Á.R. Machado, E.O. Ezugwu, A.M. Souza: Wear, 261 (2006) 674-685.

[22] V. Firouzdor, E. Nejati, F. Khomamizadeh, Journal of Materials Processing Technology, 206 (2008) 467-472.

[23] V. Leskovšek, M. Kalin, J. Vižintin: Vacuum, 80 (2006) 507-518.

[24] A. Akhbarizadeh, S. Javadpour, K. Amini: Materials \& Design, 45 (2013) 103-109.

[25] A. Akhbarizadeh, A. Shafyei, M.A. Golozar: Materials \& Design, 30 (2009) 32593264.

[26] K. Amini, A. Akhbarizadeh, S. Javadpour: Materials \& Design, 45 (2013) 316-322.

[27] S.S. Gill, J. Singh, H. Singh, R. Singh: International Journal of Machine Tools and Manufacture, 51 (2011) 25-33.

[28] N.C. KE. Moore: Key Engineering Materials, 86-87 (1993) 47-54.

[29] A. Molinari, M. Pellizzari, S. Gialanella, G. Straffelini, K.H. Stiasny: Journal of Materials Processing Technology, 118 (2001) 350-355.

[30] T.V. SreeramaReddy, T. Sornakumar, M. VenkataramaReddy, R. Venkatram: International Journal of Refractory Metals and Hard Materials, 27 (2009) 181-185.

[31] A.Y.L. Yong, K.H.W. Seah, M. Rahman: International Journal of Machine Tools and Manufacture, 46 (2006) 2051-2056.

[32] A.Y.L. Yong, K.H.W. Seah, M. Rahman: The International Journal of Advanced Manufacturing Technology, 32 (2007) 638-643.

[33] S.S. Gill, R. Singh, H. Singh, J. Singh: The International Journal of Advanced Manufacturing Technology, 58 (2012) 119-131.

[34] K. Amini, A. Akhbarizadeh, S. Javadpour: Materials \& Design, 54 (2014) 154-160.

[35] J. Yong, C. Ding, J. Qiong: Met Sci Heat Treat, 53 (2012) 589-591. 
[36] J. Indumathi, J. Bijwe, A.K. Ghosh, M. Fahim, N. Krishnaraj: Wear, 225-229, Part 1 (1999) 343-353.

[37] S. Kalia: J Low Temp Phys, 158 (2010) 934-945.

[38] K. Vadivel, R. Rudramoorthy: Int J Adv Manuf Technol, 42 (2009) 222-232.

[39] A. Bhattacharyya: Metal cutting: Theory and practice, Jamini Kanta Sen of Central Book Publishers; Rev. and enl. ed edition (1984), 2000.

[40] D. Thakur, B. Ramamoorthy, L. Vijayaraghavan: Materials Letters, 62 (2008) 4403-4406.

[41] T.V. SreeramaReddy, T. Sornakumar, M. VenkataramaReddy, R. Venkatram: Cryogenics, 48 (2008) 458-461.

[42] C.-h. Xie, J.-w. Huang, Y.-f. Tang, L.-n. Gu: Transactions of Nonferrous Metals Society of China, 25 (2015) 3023-3028.

[43] Y. Gao, B.-H. Luo, Z.-h. Bai, B. Zhu, S. Ouyang: International Journal of Refractory Metals and Hard Materials, 58 (2016) 42-50.

[44] B.L. Mordike, T. Ebert: Materials Science and Engineering: A, 302 (2001) 37-45.

[45] Y. Kojima: Materials Science Forum, 350-351 (2000) 3-18.

[46] Y. Kojima, K. Higashi, S. Kamado: Materials Science Forum, 419-422 (2003) 5156.

[47] M.X. Zhang, P.M. Kelly: Scripta Materialia, 48 (2003) 647-652.

[48] Z.W. Huang, Y.H. Zhao, H. P.D. Han: Physica B: Physics of Condensed Matter, 407 (2011) 1075-1081.

[49] K. Gu, J. Wang, Y. Zhou: Journal of the Mechanical Behavior of Biomedical Materials, 30 (2014) 131-139.

[50] J.W. Kim, J.A. Griggs, J.D. Regan, R.A. Ellis, Z. Cai: International endodontic journal, 38 (2005) 364-371.

[51] S.S. Gill, J. Singh: Materials and Manufacturing Processes, 25 (2010) 378-385.

[52] K. Gu, H. Zhang, B. Zhao, J. Wang, Y. Zhou, Z. Li: Materials Science and Engineering: A, 584 (2013) 170-176. 